\title{
Почему падают темпы роста мировой экономики. Точка зрения
}

Ю.С. ЕРшОВ, Институт экономики и организации промышленного производства СО РАН, Новосибирск. E-mail: eryus@mail.ru

Долговременная тенденция - снижение темпов роста мировой экономики и особенно экономики развитых стран. Ее нельзя объяснить влиянием только классических факторов - динамикой численности населения и ограниченностью природных ресурсов. В статье показано, что есть много других причин, объясняющих наличие такой тенденции и как их действие ухудшает экономическую динамику. Показано также, что нельзя непосредственно интерпретировать статистические данные, отражающие динамику уровня жизни.

Ключевые слова: темпы роста экономики, границы производства, товарное производство и самообслуживание, глубина переработки, насыщение рынка, производительность труда, специализация производства, уровень жизни, темпы инфляции, структура потребления

Начало XXI века ознаменовалось резким снижением темпов экономического роста развитых стран. И это не какой-то временный феномен, а продолжение долговременной тенденции. Ухудшение экономической динамики в развитых странах оказалось настолько значительным, что обусловило и замедление темпов роста всей мировой экономики - среднегодовые темпы по планете в целом составляли в 1971-1985 гг. 103,4\%, в 1986-2000 гг. $103,1 \%$, в 2001-2015 гг. - 102,6\% ${ }^{1}$. И это несмотря на очень высокие в течение последних 30 лет среднегодовые темпы роста экономики Китая и Индии при постоянно возрастающей доле этих стран в мировой экономике. Да и постсоветские страны в XXI веке показывали среднегодовые темпы роста намного более высокие, чем в 1986-2000 гг., когда прирост ВВП в целом за период был вообще отрицательным. Основная «заслуга» в ухудшении экономической динамики принадлежит развитым странам (таблица).

В далеком прошлом (1950-е, 1960-е, начало 1970-х гг.) остался период экономических «чудес» - японского, итальянского, германского и т.д., когда в отдельные периоды прирост

${ }^{1}$ Рассчитано по данным, приведенным в seosait.com/dinamika-vvp-mira-1970-2016 
ВВП мог измеряться даже двузначными числами (Япония) или в разы превышающими современные - 6, 7\% и более (Италия, Франция, ФРГ).

Среднегодовые темпы роста экономики развитых стран в периоды 1986-2000 rг. и 2001-2015 rг., \%

\begin{tabular}{|l|c|c|}
\hline \multicolumn{1}{|c|}{ Страна } & $\mathbf{1 9 8 6 - 2 0 0 0}$ & $\mathbf{2 0 0 1 - 2 0 1 5}$ \\
\hline США & 103,4 & 101,7 \\
\hline Япония & 102,4 & 100,8 \\
\hline Германия & 102,4 & 101,1 \\
\hline Франция & 102,4 & 101,1 \\
\hline Италия & 102,1 & 100,0 \\
\hline Канада & 102,9 & 101,9 \\
\hline Великобритания & 102,8 & 101,6 \\
\hline Испания & 103,5 & 101,5 \\
\hline Южная Корея & 107,8 & 103,8 \\
\hline
\end{tabular}

Источник: Рассчитано по данным, приведенным на ereport.ru со ссылкой на CIA World Factbook

Если посмотреть наличные долгосрочные прогнозы развития экономик разных стран, то ожидание дальнейшего падения темпов роста очевидно. Но в предыдущем 15-летии падение темпов оказалось настолько значительным, что более вероятной считается их временная коррекция, с последующим восстановлением долговременного тренда снижения. И никто уже не ждет продолжения китайского экономического чуда, когда в течение трех десятилетий среднегодовые темпы роста ВВП страны превышали $110 \%$.

В чем же причина снижения темпов экономического роста? Действиями только классических факторов этого объяснить нельзя. Да, темпы роста населения мира падают - если в 1971-1985 гг. они в среднем за год составляли 101,8\%, в 1986-2000 гг. $101,6 \%$, то в 2001-2015 гг. снизились до 101,2\%. Соответственно, падают и темпы роста потенциальной рабочей силы. Но это не столь значительное падение, чтобы объяснить негативную динамику темпов экономического роста, тем более, в расчете на душу населения - при стабильном населении увеличивать душевой ВВП все-таки проще, чем при быстро растущем.

Ограниченность сельхозугодий и площади морей и океанов может объяснить снижение темпов роста только сельскохозяйственного производства и рыболовства, а это для развитых стран 
очень малая часть экономики. Запасов нефти и газа на планете оказалось намного больше, чем считали несколько десятилетий назад. Растут издержки добычи, но ведь речь идет не о чистом, а о валовом внутреннем продукте, львиная доля издержек здесь - это капитальные затраты, а износ основного капитала является составной частью ВВП. Резкое повышение мировых цен на энергоносители может объяснить снижение темпов роста в странах, импортирующих нефть и газ, но не по мировой экономике в целом.

Невозможность объяснить тенденцию снижения темпов экономического роста действием классических факторов заставляет задуматься о том, что есть и другие причины, о которых в учебниках по экономике обычно не упоминается, но которые, на наш взгляд, являются достаточно значимыми.

\section{Первая причина - статистика регистрирует только итоги} товарного производства. Результаты самообслуживания в границы производства не включаются, за редким исключением так называемых «условно исчисленных услуг, которые хозяева дома или квартиры получают от собственного жилья». В России и постсоветских странах к этому нужно добавить результаты натурального, т.е. нетоварного сектора сельскохозяйственного производства.

По мере роста производства и доходов уровень его товарности растет, а доля самообслуживания снижается, в итоге темпы роста той части производства, которую учитывает статистика, опережают темпы роста производства в целом, включающего и результаты самообслуживания. Таким образом, получается, что в прошлом темпы роста производства в целом были ниже темпов его части, регистрируемой статистикой. Но уровень товарности не может расти бесконечно, и при высоких его значениях рассчитываемые статистикой темпы приближаются к темпам роста производства в целом. Прежде всего в развитых странах, уже исчерпавших львиную долю тех резервов роста, которые имели место при низкой степени товарности.

Огромные межстрановые различия в степени товарности производства позволяют объяснить кажущуюся на первый взгляд несуразной дифференциацию в душевых показателях ВВП между развитыми и отсталыми странами. Если посмотреть на результаты регулярно публикуемых международных 
сопоставлений, то первым вопросом должен стать следующий: как же живут или выживают люди в тех странах, где душевой ВВП составляет лишь 10; 5 или даже $2 \%$ от принятого за эталон показателя США? Что будет со средним американцем, если его доход сократится в 20 раз? Этих денег едва хватит на то, чтобы один раз в день поесть в дешевом кафе. А со средним россиянином, если его доход сократится в 10 раз, до, например, таджикского уровня²? Он просто умрет от голода и холода! Между тем жители Таджикистана или Киргизии, где душевой ВВП составляет соответственно 5 и 7\% от уровня США ${ }^{3}$, живут, и если верить нашим статистическим справочникам, средняя продолжительность жизни у них почти не уступает или даже выше, чем в России ${ }^{4}$ И живут они отнюдь не по стандартам средних веков, когда текущие потребности людей ограничивались лишь скромными питанием и одеждой. Конечно, источником средств существования для граждан Таджикистана или Киргизии является не только ВВП, произведенный на их территориях, но и то, что они зарабатывают за ее пределами. Но радикальных изменений в межстрановые различия учет этого фактора не принесет - 5 и 7\% превратятся соответственно в 8 и $9 \%$. Но это в среднем, а как же живут бедные люди?

Низкие душевые показатели производства и потребления отсталых стран в значительной степени объясняются низкой степенью товарности их производства, т.е. тем, что статистика регистрирует лишь меньшую часть результатов экономической деятельности. Де-факто многодетные родители, считающиеся незанятыми в экономике, но работающие с утра до вечера и без выходных, могут производить товаров и услуг больше, чем многие формально занятые граждане развитых стран. Детей на одну маму здесь может быть даже больше, чем приходится на одного сотрудника детского сада у передовиков мировой

\footnotetext{
${ }^{2}$ Из данных, приведенных в разделе «Международные сравнения» Российского статистического ежегодника (2016 г.), следует, что душевой ВВП в Таджикистане в 2011 г. был в 10 раз меньше, чем в России.

${ }^{3}$ Из данных, приведенных в этом же справочнике.

${ }^{4}$ Из данных, приведенных в этом же справочнике, следует, что в Таджикистане средняя продолжительность жизни (при рождении) в 2014 г. составляла 73,4 года, в то время как в России даже в 2015 г. она была лишь 71,4. Относительно высокий показатель продолжительности жизни в Таджикистане скорее всего завышен вследствие неполной регистрации фактов младенческой и детской смертности. Но тем не менее.
} 
экономики. И продолжительность «трудовой смены», и круг обязанностей намного больше. Но все, что делает эта мама, статистика не считает.

Можно ли поднять показатели душевых ВВП бедных стран для обеспечения большей сопоставимости межстрановых показателей производства и потребления? Легко, и без всяких иностранных инвестиций! Но вряд ли какой-нибудь разумный правитель использует этот рецепт. Для этого лишь нужна специализация производства, добровольная или принудительная. Пусть в каждом кишлаке Зульфия займется приготовлением пищи не только для своей семьи, но и для соседей, т.е. организует общественную столовую. Гюли со старшими дочерьми займется присмотром за детьми, т.е. организует детский сад. Фатьма хорошо шьет, и у нее есть швейная машина - пусть она шьет и перешивает одежду для всей округи. У Гюльчетай есть стиральная машина, утюг и гладильная доска - она займется стиркой для всех соседей. На чем-то смогут специализироваться и их «незанятые в экономике» мужья. И тогда за свою работу Зульфия, как и все остальные, будет получать деньги и, естественно, в большем объеме, чем это требуется для приобретения продуктов, необходимых для приготовления пищи, потому что она должна будет за счет своей выручки оплачивать те услуги, которые ей оказывают Гюли, Фатьма, Гюльчетай и их мужья. То, что тратит Зульфия на продукты, будет теперь промежуточным потреблением по ее виду деятельности, все остальное - добавленная стоимость. Производство станет товарным, и его результаты можно будет включать в ВВП страны. Конечно, для осуществления такой реформы потребуется увеличить количество денег в обращении, но это дело технически несложное.

Но это еще не все. Если раньше и плита Зульфии, и швейная машина Фатьмы, и стиральная машина Гюльчетай были просто потребительскими товарами, то теперь они станут средствами производства - их можно будет поставить на баланс, начислять амортизацию, и это тоже будет прибавка к валовому внутреннему продукту. Так же можно будет поставить на баланс и автомобиль или мотоцикл, или даже рабочую лошадь или ишака, с помощью которых специализирующиеся на отдельных видах деятельности их мужья станут производить товарную продукцию. В результате от такой реформы ВВП бедной страны может вырасти в разы. 
Но жизнь от этого вряд ли станет лучше, скорее, людям будет как-то непривычно, неуютно.

И это одна из причин для выдвижения гипотезы о необязательности наличия прямой связи между душевыми показателями производства (потребления), регистрируемыми статистикой, и фактическим уровнем жизни или благосостояния.

Следует ли из вышесказанного, что существующая статистика имеет огромные недостатки и ее следует изменить в направлении более полного учета итогов экономической деятельности, в том числе и самообслуживания? Скорее всего, нет. Во-первых, на такую реформу не пойдет законодатель моды в современной статистике - мировой капитал в лице развитых стран, для которых актуальность проблемы недоучета итогов самообслуживания невелика. Во-вторых, бедная страна от такой реформы статистики богатой не станет $-5 \%$ от американского уровня могут превратиться, возможно, в 25 или даже $30 \%$, но не в 80 или $120 \%$. Просто формальные показатели производства придут в большее соответствие с показателями потребления, измеряемыми в самых надежных, натуральных показателях - сколько на душу населения приходится калорий, белков, углеводов и витаминов, тех или иных предметов длительного пользования.

Но не это главное. Если пытаться учитывать все результаты самообслуживания, то вообще будет неизвестно, где заканчиваются границы производства - почти все, что мы делаем, имеет рыночные товарные аналоги. Проснулся, причесался, накрасил ногти, почистил обувь и одежду, приготовил или разогрел завтрак, помыл посуду, собрал ребенка в школу - но это могла бы сделать наемная прислуга или профессионал из парикмахерской и кафе. Кто и как будет это считать, сопоставлять и т.д.? Сколько и каких специалистов потребуется, чтобы определить, что человек съел не сахар, яйцо, муку, а приготовил из них торт, который в магазине стоит в два-три раза дороже исходных материалов? И как определить, когда вы за рулем собственной машины «работали» - например, ехали на службу будучи сами для себя «таксистами», или же «просто катались», потому что вам нравится водить машину. И так далее.

Конечно, очень интересно было бы узнать фактические масштабы производства и потребления товаров и услуг и реальные межстрановые различия. Представьте себе, что эфиопская мама 
сварила ребенку кашу, покормила, спела колыбельную, уложила спать, и «Эфиопстат» учитывает итоги этой работы в составе ВВП страны, причем по принципу «паритета покупательных способностей», т.е. эта работа оценивается таким же количеством долларов и центов, какое за такие же действия получает наемная няня в американской семье - от $1-2 \%$ на душу населения по сравнению с США не останется и следа.

Повышение степени товарности производства - не единственный фактор, объясняющий общую долговременную тенденцию снижения темпов экономического роста, да и достаточно значимым он является лишь для развитых стран. Есть и другие причины.

Вторая причина - исчерпание разумных пределов глубины переработки сырья. Она в значительной степени пересекается с первой - снижением доли самообслуживания - и в значительной степени объясняет рост производства, например, в легкой, и особенно пищевой промышленности. Когда-то в магазинах многие покупали не готовые изделия, а ткань или шерсть, и сами шили, вязали. Сегодня в развитых странах это редкость. Снижение спроса на исходные материалы - это, безусловно, результат роста уровня доходов. Однако многие изделия современной легкой промышленности сделаны из таких материалов, которых в продаже просто-напросто не найдешь, даже если у кого-то возникает желание сделать такое изделие самому.

Когда-то мы в основном покупали сырое мясо, рыбу, фляжное молоко. Сейчас все чаще - в виде полуфабрикатов, копченостей, нарезок в вакуумных упаковках, в бутилированном и глубоко переработанном виде, да еще в невозвратной таре и упаковке, стоимость которых входит в общий объем продукции пищевой промышленности. Это тоже в основном результат роста уровня доходов. Но не только. Нередко имеет место и принуждение к потреблению более глубоко переработанной и более дорогой продукции. Например, продажа «сырого» молока на розлив фактически запрещена. Немытые овощи и фрукты, сырое мясо или рыбу, которые не едят без термической обработки, продавать можно, а молоко - нет, хотя оно было бы значительно дешевле, чем бутилированное пастеризованное, и многих вполне устраивало, так как необходимо для приготовления каш, молочных супов и омлетов, где глубина термической обработки даже выше, чем 
при пастеризации. Но если разрешить его свободную продажу, объемы производства в молочной промышленности и соответствующая часть ВВП сократятся.

А что будет с нашей мясной или рыбной промышленностью, если мы, например, в плане перехода к более здоровому питанию, откажемся от покупки колбас, копченостей, нарезок и консервов и будем покупать только мясо на кости и сырую рыбу? Половину персонала мясо- и рыбоперерабатывающих предприятий придется уволить со всеми вытекающими негативными последствиями для величины добавленной стоимости. А если, напротив, откажемся от покупок «пищевого сырья» и будем приобретать только продукты, уже готовые к употреблению или, в худшем случае, требующие только разогрева?

В значительной степени «увеличение глубины переработки» имеет место и в секторе непродовольственных товаров, если под этим подразумевать переход от изделий, состоящих из отдельных деталей, к изделиям, состоящим из крупных неразборных узлов или вообще неразборным. Это тоже в целом положительный результат технического прогресса - степень автоматизации в поточном производстве такова, что издержки на новое изделие сопоставимы или даже меньше, чем затраты на ремонт.

Резервы роста производства за счет увеличения глубины переработки сырья еще есть, но влияние этого фактора с течением времени сокращается. Теоретический предел в части непродовольственных товаров - никаких ремонтов, при любой поломке старое изделие выбрасывается и приобретается новое - в полном объеме вряд ли будет достигнут, но круг изделий, не подлежащих ремонту или которые ремонтировать дороже, чем купить новое, постоянно расширяется.

Третья причина - насыщение потребительского рынка основными товарами. Нет никаких проблем с наращиванием производства продукции, когда у многих или большинства потребителей еще нет телевизоров, холодильников, автомобилей, компьютеров, мобильных телефонов, когда у них еще скуден гардероб или мало мебели. Или когда еще много недоедающих и т.д. Но вот уже все или почти все сыты, одеты, все, кто может и хочет иметь машину, уже ее купил. Как расти экономике дальше? Только побуждая потребителей все чаще избавляться от «старого» и покупать новое. Это уже сложнее. 
Насыщение рынка часто приводит к сильному снижению темпов роста в отдельных отраслях. Наглядный пример - наша отечественная связь, особенно мобильная, когда-то бурно развивавшаяся, а теперь почти замершая в развитии. Почти у всех уже есть мобильники. Зоны доступности можно расширять и дальше, но это уже дорого и не даст много новых клиентов. Будут ли люди при увеличении доходов тратить на разговоры все больше и больше времени? Может, и будут, но ненамного. Здесь тоже есть пределы объемов потребления. Значит, надо постоянно придумывать что-то новое, более дорогое, и побуждать потребителей к приобретению новых средств связи и пользованию новыми услугами.

\section{Четвертая причина - при повышении уровня доходов структура потребительского спроса смещается в сторону товаров и услуг, где возможности роста производительности} труда ограничены или отсутствуют вообще. Это касается прежде всего услуг. Именно по этой причине цены на услуги растут заметно быстрее, чем цены на товары. Но и в сфере товарного производства есть такие отрасли, где резервы роста производительности крайне ограничены. Прежде всего это энергетика, водо- и газоснабжение. В развитых странах почти все процессы в этих сферах уже механизированы и автоматизированы, люди просто наблюдают и осуществляют ремонтное обслуживание. Но убрать наблюдателей или аварийно-ремонтные бригады, которые в штатных ситуациях практически ничем не заняты, нельзя.

В сфере услуг с ростом производительности все гораздо хуже, но не из-за высокого уровня механизации и автоматизации. Как повысить производительность работников образования? Увеличить количество детей в группах детских садов или учеников в школьных классах? А что делать в здравоохранении? Сложными высокими технологиями занимается очень малая часть из этой сферы. Выпуск в текущих ценах в этих отраслях, конечно, растет, но индексы физического объема почти на нуле.

Как повысить производительность труда работников общественного питания? Предлагать посетителям все более дорогие блюда или ограничиваться только подогревом полуфабрикатов, расфасованных на фабриках? А, например, на городском транспорте? Увеличивать размеры транспортных средств нельзя, скорость тоже. Можно, конечно, уменьшить количество 
транспортных средств и пусть они все будут битком набиты, по показателю пассажирокилометров на одного водителя будет большой прогресс. Но такого рода услуги современному потребителю не нужны.

Во многих случаях производительность труда в сфере услуг даже снижается, несмотря на радикальную замену материальнотехнической базы. Просто в связи с ужесточением требований и стандартов. Прежде всего это финансовая деятельность на каждого клиента-вкладчика времени сейчас тратится намного больше, чем в советские времена или в начале рыночных реформ. И на оплату всех счетов ЖКХ и т.п. сейчас уходит намного больше времени, чем в прошлом, если это делается, конечно, традиционным способом, требующим личной явки в платежный пункт.

Огромные перспективы в плане повышения производительности труда, вроде бы, сулили инновации в такой крупной по численности занятых отрасли, как розничная торговля. По сравнению с древней технологией обслуживания без кассовых аппаратов штрих-коды на упаковках, быстрое и безошибочное вычисление итоговых сумм - настоящий прогресс. Но штрихкоды надо наносить, и кто-то это делает, мы просто этих людей не видим, а они «за кулисами» фасуют и взвешивают продукты. В случае поломки или перебоев в электроснабжении кассовый аппарат может перестать работать и магазин просто «встанет». Теперь требуют перехода к онлайн-кассам - здесь вообще никакого роста производительности труда не будет, только лишь рост издержек и возможные простои еще по одной, новой причине - «зависания» оборудования. И, к слову, ящик водки или коробку вина теперь уже быстро не купишь - ЕГАИС требует индивидуального учета каждой отдельной бутылки.

Причина пятая - исчерпание резервов роста экономики развитых стран вследствие специализации на наиболее выгодных видах деятельности. Какие виды деятельности в современной рыночной экономике являются самыми высокодоходными в расчете на одного занятого? Финансы, оптовая торговля и разного рода посредничество. Чтобы они приносили все больший доход, необходима внешняя экспансия - расширение рынков обслуживания. Работа только на внутреннюю экономику к росту ВВП не приведет, в лучшем случае - даст только перераспределение результатов. 
Обслуживая другие страны - предоставляя им кредиты, осуществляя платежи, страхуя их риски и т.д., можно собирать сливки, т.е. получать самые легкие доходы. Пока возможности внешней экспансии не исчерпаны, можно продолжать перераспределять мировой ВВП в свою пользу. Но как быть, если охвачена почти вся планета?

В миниатюре последствия такой экспансии мы наблюдали на примере нашей столицы. Имевшая всего 9\% от суммарного ВРП в 1995 г., она смогла к 2008 г. поднять этот показатель до 24\%. Без всякого развития промышленности - темпы еe роста в Москве уже давно на нуле. Просто за счет специализации на самых выгодных видах деятельности и концентрации здесь головных офисов крупнейших корпораций.

Из всего изложенного выше можно прийти к очевидному выводу о том, что потенциальные резервы роста у бедных стран намного больше, чем у богатых. Смогут ли они реализовать эти возможности и при каких условиях - это уже предмет другого исследования. А в заключение логично рассмотреть еще один важный вопрос-можно ли верить показателям динамики уровня жизни?

Если производство в целом, включая самообслуживание, росло медленнее, чем регистрируемая статистикой его часть, то, по всей видимости, медленнее должно было расти и потребление в целом. Что такое потребление в целом и какова его динамика, вопрос достаточно сложный, поэтому логично эту тему сузить отражают ли показатели динамики реальных денежных и других доходов действительный их рост или Росстат вольно или невольно приукрашивает действительность?

Точный ответ дать невозможно, особенно при сопоставлении далеко отстоящих друг от друга временных точек. Скорее всего, искажения, если они и есть, минимальны. За динамикой потребительских цен следят многие независимые организации, она видна всем гражданам, и здесь сильно не обманешь.

Но если можно принять тот факт, что показатели динамики реальных доходов верны, то никак нельзя согласиться с их непосредственной интерпретацией. Если верить статистике, то к началу 2017 г. по сравнению с концом 1990-го средний уровень цен на товары и услуги увеличился в 95500 раз, с учетом деноминации - в 95,5 раз. Такой результат дает произведение 
годовых индексов. Для простоты сопоставлений можно принять цифру 100 . Но можно ли считать, что человек, имеющий сейчас доход 20000 руб. в месяц, имеет тот же достаток, как и получавший в 1990 г. 200 руб. («чистыми», конечно)? Кто постарше, наверняка скажет «нет». А почему?

Если просто сравнивать цены, можно найти очень много товаров и услуг, цены на которые выросли менее чем в 100 раз, т.е. относительно подешевели, некоторые даже в разы. Среди них и продукты питания, и много промышленных товаров. Водка, яйца, мясо кур, фрукты, сахар, шоколад и конфеты, мука, телевизоры, магнитолы, одежда, автомобили и многое другое. И, конечно, есть много товаров, прежде всего продуктов питания, цены на которые выросли более чем в 100 раз. Молоко, хлеб, соль, простая рыба, почти все услуги. В чем же проблема, почему сегодня на 20000 руб. жить сложнее, чем в 1990 г. на 200 руб.?

При расчете динамики реальных доходов статистика игнорирует очень многие факторы, которые можно объединить в несколько групп. Первая группа факторов - на официальных показателях никак не отражаются факты прекращения предложения многих товаров и услуг. Естественно, в первую очередь исчезают самые дешевые из них. Перечень таких примеров может быть очень длинным. Скажем, вам надо ехать до города Энска, всего часов пять-шесть, и раньше вы могли взять билет в самый дешевый общий вагон. Теперь поезд стал «фирменным», общих вагонов нет, и в цену билета включена стоимость даже постельного белья, даже если оно вам и не понадобится.

Вы небогатый человек, но нужна машина, и вы согласны ездить на самых простых «Жигулях» или даже на «Оке», но таких уже не делают. Даже сэкономить на отказе от электроподъемников, тахометра, климат-контроля и прочих прилад не получится - таких новых машин нет. Когда-нибудь они исчезнут и со вторичного рынка. Нет дешевых стиральных машин с ограниченным числом функций, управляемых вручную, нет черно-белых телевизоров, нет (или горожанам трудно его достать) упоминавшегося выше фляжного молока. Раньше стал заканчивать работу городской транспорт; если припозднился, остается только такси. Не производятся больше самые дешевые мобильные телефоны с минимальным набором традиционных функций. И т.д. 
Вторая группа факторов - появление принудительно навязываемых товаров и услуг. Факт принуждения на индексах роста цен никак не отражается, равно как и появление любой новой дорогой услуги, которой раньше просто не было. Помимо навязывания уже упомянутых автомобильных «наворотов», постельного белья в поездах, простые примеры - ОСАГО, обязанность приобретать водяные и электрические счетчики, оплачивать их проверку. А сколько приходится платить за оформление и переоформление прав собственности на жилье, земельные участки, дачи, гаражи! А до рыночных реформ «продавец» дачи или гаража не тратил ни копейки, расходы «покупателя» ограничивались скромным вступительным взносом; расходы граждан, желающих осуществить обмен неприватизированных квартир, состояли лишь из символической платы за обменный ордер. Значительные суммы теперь приходится платить нотариусам, фирмам по оценке стоимости имущества при оформлении наследственных прав. И, естественно, налоги, многих из которых раньше просто не было, а их появление никак не учитывается при расчетах индексов цен на товары и услуги.

Третья группа факторов - необходимсть иметь то, без чего ранее легко обходились. Это формально не является принуждением, но по сути для большинства людей даже не стоит вопрос - «иметь или не иметь». Иметь. Самый яркий примермобильный телефон, который есть у многих обладателей и домашнего, и рабочего телефона. Даже ребенка в школу отправляют с мобильником с самых первых классов. Жить без него и Интернета стало очень трудно, а для кого-то просто невозможно. Как посмотрит на вас потенциальный работодатель, если вы в своем резюме напишете, что у вас нет мобильного телефона или электронного почтового адреса?

Четвертая группа факторов - все большее распространение так называемого статусного потребления. Это тоже фактически принуждение к дополнительным расходам, сопряженное с желанием «не ударить в грязь лицом» перед друзьями и знакомыми. Это особенно чувствуют те, у кого есть дети. У всех в классе крутые смартфоны, как в этом случае дать ребенку старенький аппарат просто для связи? Ему будет очень некомфортно. Подружка пригласила на день рождения, оказалось, что все празднество будет в кафе, с затейником, общий 
бюджет - 30000 руб. Теперь придется отвечать адекватно, пусть и скрепя сердце, за счет экономии на более насущных нуждах. Но статистика никак не учитывает ту степень удовольствия, которую вы получили, истратив эти 30000 руб.

Вы выбираете марку машины, часов, гаджетов в соответствии со своим статусом и рангом в служебной иерархии, участвуете в каком-нибудь организуемом вскладчину мероприятии, чтобы не отрываться от большинства. И так далее.

Именно эта группа факторов определяет фактическую дороговизну жизни в Москве. И не на $27 \%$ по сравнению со среднероссийским показателем стоимости жизни, как следует из нашей статистики, а гораздо больше. И не потому, что в столице дороже бытовая техника, одежда и продукты питания. Получая 30 тыс. руб. в месяц, житель какого-нибудь провинциального города, наверняка чувствует себя более комфортно, чем москвич с зарплатой в 38100 руб.

Эти тренды очень устойчивы: жизнь будет изменяться в сторону, требующую увеличения расходов в большем размере, чем это диктуется темпами инфляции. Могут ввести обязательное страхование жилья (такая идея уже обсуждалась), и это никак не отразится на темпах роста цен. Могут обязать автопроизводителей оснащать машины «черными ящиками», чтобы облегчить поиск причины и виновников транспортных происшествий и аварий. Машины станут дороже, но это будут другие машины. Могут фактически обязать население оснащать квартиры и дома сигнализацией и видеокамерами, чтобы было легче расследовать совершаемые в них уголовные преступления (а иначе плата за страхование будет существенно выше). Фантастикой это уже не кажется.

В заключение необходимо отметить, что уровень жизни или благосостояния в житейском понимании - понятие, не имеющее строгого определения и количественной оценки, и он далеко не всегда прямо связан с динамикой реальных доходов. У человека, как и у страны в целом, также есть фонд потребления и фонд накопления. И пока последний положителен, уровень жизни может расти даже при снижении реальных доходов. Была, например, зарплата 100 тыс. руб., снизилась до 80 тыс. руб. На текущие нужды продолжает уходить, например, 30 тыс. руб. Рост уровня жизни такого человека будет продолжаться и при 
пониженных денежных доходах, но не так быстро. Просто медленнее будет идти процесс приобретения «основных средств»бытовой техники, мебели; позже и не такой дорогой, будет куплен автомобиль, придется сначала приобрести однокомнатную квартиру, а не сразу «двушку». Падение уровня жизни грозит «лишь низкооплачиваемому большинству», которое при снижении денежных доходов будет вынуждено сократить расходы на текущие нужды. Высокооплачиваемые в период кризиса и сокращения текущих доходов могут даже выиграть, если, например, кризис классический и сопровождается значительным снижением цен на недвижимость - накопленные ранее суммы могут стать достаточными для приобретения более комфортного жилья.

А по отдельным позициям рост уровня жизни продолжается и для населения в целом даже в периоды очень глубоких и длительных кризисов, как это было в России в 1990-х гг. увеличивался метраж жилого фонда на душу населения, росли количество личных автомобилей и степень телефонизации жилого фонда, равно как число холодильников, телевизоров, пылесосов, магнитол, не говоря уже о видеомагнитофонах и персональных компьютерах, которые в конце 1980-х были редкостью или вообще отсутствовали.

Резюмируя все изложенное, приходим к выводу о том, что многие статистические показатели отражают реальную динамику с определенной долей условности. Даже в таком, казалось бы, простом случае, как оценка динамики уровня жизни, где, на первый взгляд, ничего не надо знать, кроме величины номинальных доходов и индексов роста цен на товары и услуги. Идеальных макроэкономических показателей, допускающих непосредственную интерпретацию изменений значений объемов производства и потребления, просто не существует. 